\title{
Alfred De Musset, Poésies complètes
}

\section{Valentina Ponzetto}

\section{(2) OpenEdition}

\section{Journals}

\section{Edizione digitale}

URL: https://journals.openedition.org/studifrancesi/26578

DOI: 10.4000/studifrancesi.26578

ISSN: 2421-5856

\section{Editore}

Rosenberg \& Sellier

\section{Edizione cartacea}

Data di pubblicazione: 1 avril 2007

Paginazione: 199

ISSN: 0039-2944

\section{Notizia bibliografica digitale}

Valentina Ponzetto, «Alfred De Musset, Poésies complètes», Studi Francesi [Online], 151 (LI | I) | 2007, online dal 30 novembre 2015, consultato il 23 novembre 2021. URL: http://journals.openedition.org/ studifrancesi/26578; DOI: https://doi.org/10.4000/studifrancesi.26578

\section{Questo documento è stato generato automaticamente il 23 novembre 2021.}

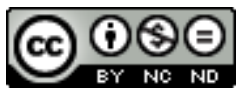

Studi Francesi è distribuita con Licenza Creative Commons Attribuzione - Non commerciale - Non opere derivate 4.0 Internazionale. 


\title{
Alfred De Musset, Poésies complètes
}

\author{
Valentina Ponzetto
}

\section{NOTIZIA}

ALFRED DE MUSSET, Poésies complètes, édition présentée, établie et annotée par Frank LeSTRInGant, Paris, Livre de Poche, «Classiques de Poche», 2006, pp. 896.

1 Frank Lestringant ci ha ormai abituati alle sue belle edizioni delle opere di Musset che uniscono al rigore dell'approccio al testo la finezza e l'originalità di un'analisi sempre innovativa, che spinge al confronto critico con tradizioni interpretative troppo spesso date per scontate.

Questa nuova edizione delle Poésies complètes di Musset ne è una brillante conferma a partire dalla scelta stessa del testo da adottare come riferimento. Una vecchia consuetudine editoriale fino ad oggi mai messa in discussione voleva infatti che ci si basasse sull'ultima edizione apparsa durante la vita di Musset, quella del 1854, scelta seguita ancora, per non citare che due esempi autorevoli, da Maurice Allem per la «Pléiade» e più recentemente da Jacques Bony per i due volumi tascabili «GFFlammarion» del 1998. Ma, come fa giustamente notare Lestringant, la scarsa attenzione che Musset aveva sempre prestato all'edizione dei suoi testi col passare del tempo era diventata una quasi totale indifferenza. Aveva così finito per permettere agli editori di decidere liberamente ed arbitrariamente l'ordine da dare ai poemi e per lasciar passare inosservate coquilles, parole mal trascritte, versi dimenticati. Per la presente edizione il critico ha dunque scelto di basarsi su quella del 1840, che un Musset appena trentenne intitolava già, significativamente, Poésies complètes, come se nulla vi fosse più da aggiungere. Le opere scritte dopo tale data appaiono qui in ordine rigorosamente cronologico e il più possibile rispettoso delle scelte dell'autore. Alle Poésies nouvelles (1840-1849), pubblicate come tali nel 1850, fanno così seguito $\mathrm{i}$ Compléments del 1852, quattro poemi di più vecchia data ma pubblicati solo in quel momento, e le due sezioni, già adottate da Maurice Allem, di Poésies complémentaires e Poésies posthumes. Un tale inedito ordinamento - sottolinea il critico - «épouse au plus 
près le développement de l'oeuvre de Musset, tel qu'il apparut aux contemporains, par dévoilements progressifs». Anche i testi sono stati restituiti il più possibile al loro aspetto originale, grazie al ripristino degli spazi bianchi, in genere omessi, delle partizioni in strofe, della punteggiatura mussettiana, ristabiliti grazie ad un accurato lavoro di verifica sulle edizioni originali e preoriginali dei testi, nonché sui rari manoscritti autografi conservati.

3 Tale scelta abbina al rigore filologico un'acuta proposta interpretativa. Essa permette infatti di abbandonare la tradizionale bipartizione, puramente editoriale, del corpus poetico di Musset in Premières poésies e Poésies nouvelles, per ritrovare un disegno e un'intenzione dell'autore nell'organizzare la sua raccolta, in barba all'immagine imperante di un Musset poeta rapsodico, episodico, d'occasione. Quest'immagine, ci avverte Lestringant nell'introduzione, è certamente valida per gli anni di precoce declino del poeta, quando diventa difficile, anche se non impossibile, individuare dei fili conduttori in una poesia sempre più dispersa e dispersiva. Ma nella raccolta del 1840 egli individua una solida ed equilibrata struttura tripartita, corrispondente alle tre età creative evocate nel celebre sonetto liminare: i Contes d'Espagne et d'Italie tradurrebbero l'insolenza dell'infanzia, Un spectacle dans un fauteuil la foga dell'adolescenza e le Poésies nouvelles, con il loro disteso lirismo, la conquista di un precario equilibrio e dell'età adulta. Centro e culmine della raccolta, Un Spectacle dans un fauteuil cerca la fusione sperimentale di poesia e teatro, in un sogno di arte totale che anticipa Mallarmé o Wagner.

4 In effetti, ricorda ancora l'introduzione, Musset, così tanto criticato o deriso dalle successive generazioni di poeti, si rivela spesso, imprevedibilmente, un loro precursore, quando non un loro inconfessato modello. Vale dunque la pena di (ri)leggere o (ri)scoprire questo romantico atipico, «le plus iconoclaste peut-être des poètes du XIX ${ }^{\mathrm{e}}$ siècle avant Rimbaud», i suoi versi tramati di allusioni letterarie fra il serio e l'ironico, che il ricchissimo apparato di note ci aiuta a delucidare, il suo lirismo ingannevolmente soggettivo, che fa continuamente appello alla collaborazione complice del lettore per trovare piena realizzazione. 